Check for updates

Cite this: Mater. Adv., 2022, 3,3208

\title{
Mesoporous silica-based abrasion resistant antireflective (AR)-cum-hydrophobic coatings on textured solar cover glasses by a spray coating technique $\dagger$
}

\author{
Srikrishna Manna, ${ }^{\text {ab }}$ Milan Kanti Naskar (D) ${ }^{a}$ and Samar Kumar Medda (D) *a
}

\begin{abstract}
The present work describes the fabrication of functionalized mesoporous silica based antireflectivecum-hydrophobic coatings on textured solar cover glasses via a spray-coating technique; the fabricated coatings exhibit good abrasion resistance. The thicknesses of the AR and hydrophobic layers have been varied in the ranges of 350-500 nm and $30-45 \mathrm{~nm}$, respectively. The application of a bilayer coating on textured solar cover glass resulted in a significant enhancement of $\geq 4 \%$ in the average solar transmission in the wavelength range of 400-1100 nm. A hydrophobic coating with self-cleaning properties was designed on the mesoporous silica coating, and it exhibited an enhancement of the photo-current density $\left(\mathrm{mA} \mathrm{cm}{ }^{-2}\right.$ ) of $4.65 \%$ under simulated solar light of 1 sun with a maximum output power enhancement of $\geq 4 \%$ based on $1-V$ (ampere-volt) characterization. After 50 cycles of sandpaper (80 mesh) abrasion testing of the coated solar cover glass, its water contact angle value was reduced from $130^{\circ}$ to $105^{\circ}$, and $50 \mathrm{~h}$ UV radiation exposure testing confirmed that there were no significant changes in the coating quality. These results indicate the good durability, abrasion resistance, and AR/hydrophobic properties of the coatings.
\end{abstract}

Received 3rd December 2021

DOI: $10.1039 / \mathrm{d} 1 \mathrm{ma} 01141 \mathrm{c}$

rsc.li/materials-advances through the solar cover glass (antireflective (AR) effect) to the solar cell, resulting in an increase in photocurrent. Presently, 'millimeter scale textured solar cover glass' (MSTSCG), which is the third-generation solar cover glass, is capable of trapping extra light, and has the advantages of antidazzle and positive temperature effects, is being used. Still, there exists ample scope for research to further improve the light-harvesting properties of such textured solar cover glasses. The lifetime of cover glasses for solar cell applications is also an important factor in fabricating solar cell modules. As the cover glass is exposed to open air, dust particles may adhere to it, reducing its transparency and thus decreasing the conversion efficiency of the solar cell module. ${ }^{1-3}$ To maintain the conversion efficiency of the solar cell at a desirable level, the cover glass must be coated with a protective, hard and hydrophobic layer with low reflective properties. The use of mesoporous silica with a relatively ordered pore structure as a coating layer has been proven to achieve better light conversion efficiency with easy cleaning and maintenance. ${ }^{4-8}$

Various approaches have been used to apply thin coatings on 'solar cover glasses' (SCGs) and solar cells to increase the efficiency and durability of the coatings deposited on solar panels or modules. Silica-based AR coatings with disordered pore structures have been reported for photovoltaic cells, ${ }^{9-14}$ solar glass and ophthalmic lenses. To improve their moisture resistance or hydrophobicity, fluorosilane $e^{4-6}$ and hexamethyldisilazane 
(HMDS) ${ }^{9}$ based precursors have been used. Some of the reported coatings have been applied on solar cover glass or solar cells and cured at high temperature with a low solar photo-current. ${ }^{15,16}$ R. Ding et al. ${ }^{17}$ developed a broadband double-layer AR coating via a solvent evaporation self-assembly method using two different mesoporous films. The broadband AR coating increases the power conversation efficiency of solar cell by $1.23 \%$ for quartz, $1.31 \%$ for borosilicate glass and $1.37 \%$ for K9 glass. Attempts were made to develop AR coatings via a sol-gel route on glass and other substrates using a single- or double-layer deposition technique. ${ }^{17-19}$ Furthermore, single-, double- or multilayer AR coatings, some with hydrophobic surfaces, on glass and solar cover glass substrates using mesoporous or low-refractive-index materials to enhance transmission or the photo-current efficiency of the solar cell have also been reported. ${ }^{20-33}$ However, these coatings showed relatively low photo-current efficiency $(<3 \%)$. Gundulahelsch et $a l .{ }^{29}$ prepared an AR coating with self-cleaning and photo-catalytic properties on solar cover glass using a $\mathrm{SiO}_{2}-$ $\mathrm{TiO}_{2}$ sol via a dip-coating technique. Vipul Jain et al. reported a silica-based nano-coating on solar glass with $3 \%$ transmission and a water contact angle range of $109-112^{\circ}$ using a dip-coating technique. $^{33}$

With these motivations, in this work, the main objective was to develop a silica-based transparent, protective, hard and hydrophobic mesoporous coating on the millimeter scale for textured solar cover glasses (MSTSCG) that would increase the transmission to $>3 \%$ and consequently enhance the output photocurrent, as well as exhibit self-cleaning properties, via the spray-coating technique. To obtain a suitable AR effect using a monolayer AR coating, the refractive index (RI) of the AR coating layer should be the geometric mean value of the refractive indices of air and the substrate $\left(n_{\mathrm{o}} n_{\mathrm{s}}\right)^{1 / 2}$. The optical glass of transparent components generally has a RI of 1.471.92. Therefore, the RI of the AR film must be in the range of 1.21-1.38. Here, the solution for the AR coating was prepared using a silica precursor in the presence of pluronic F127 as co-block polymer via a sol-gel technique. The refractive index value of the thin films was optimized by varying the concentrations of the precursors and surfactants. The coated samples were characterized using FTIR, AFM, TEM, TG and GIXRD studies, along with evaluation of the adhesion, abrasion, optical transmission, durability and $I-V$ (ampere-volt) characteristics of the coatings.

\section{Experimental details}

\subsection{Materials}

All chemicals were used as received. Tetraethyl orthosilicate (TEOS), methyltriethoxysilane (MTES), the surfactant Pluronic F127 $\left(\mathrm{EO}_{100} \mathrm{PO}_{70} \mathrm{EO}_{100} ; \mathrm{Mol}\right.$. Wt $\left.=12600 \mathrm{~g} \mathrm{~mol}^{-1}\right)$ and 1,1,1,3,3,3-hexamethyl disilazane (HMDS) were supplied by Sigma-Aldrich, while ethanol, 1-propanol, 1-butanol, $N$-methyl2-pyrrolidone, and $\mathrm{HCl}$ (35.4\%) were obtained from MERCK Specialties Pvt. Milli-Q (Millipore) water (18.2 M $\Omega$ ) was used throughout the study.
Table 1 Variation of the RI values of the thermally cured coatings derived from base coating sols having different F127 concentrations (with 6.5 wt\% of $\mathrm{SiO}_{2}$ equivalent)

Sample Concentration of F127 present RI value of the thermally cured name in the base coating sol (wt\%) coating (measured at $633 \mathrm{~nm}$ )

\begin{tabular}{lll}
\hline SF-3 & 3 & $1.355 \pm 0.005$ \\
SF-5 & 5 & $1.328 \pm 0.005$ \\
SF-6 & 6 & $1.292 \pm 0.005$ \\
SF-7 & 7 & $1.288 \pm 0.005$ \\
SF-8 & 8 & $1.269 \pm 0.005$
\end{tabular}

\subsection{Preparation of sol for AR coating}

For the preparation of nanocomposite AR coating sol, MTES $(0.0913 \mathrm{~mol})$ and TEOS $(0.1875 \mathrm{~mol})$ were mixed with 1 -butanol $(0.2844 \mathrm{~mol})$, followed by adding a mixed solution of $\mathrm{HCl}$ $(0.00122 \mathrm{~mol})$, water $(0.202 \mathrm{~mol}), 1$-butanol $(0.036 \mathrm{~mol})$ and $N$-methyl-2-pyrrolidone $(0.10 \mathrm{~mol})$ to the former solution. After stirring for 10-15 $\mathrm{min}$ at room temperature (RT) (25 \pm $2{ }^{\circ} \mathrm{C}$ ), the solution was then heated at $\sim 60{ }^{\circ} \mathrm{C}$ for $60 \mathrm{~min}$ followed by cooling at RT to obtain solution A. The surfactant F127 (0.0012328 mol) was mixed with ethanol (3.41 mol) under stirring for $1.5 \mathrm{~h}$ to obtain solution B. Solution A was added to solution B, maintaining the optimized $6.5 \mathrm{wt} \% \mathrm{SiO}_{2}$ equivalent and $6 \mathrm{wt} \%$ F127 (designated as SF-6), under stirring for 60-70 min to obtain a sol suitable for AR coating. In a similar way, by varying the surfactant concentration to 3, 5, 6, 7 and $8 \mathrm{wt} \%$, different sols were prepared and designated as SF-3, SF-5, SF-6, SF-7 and SF-8, respectively (Table 1 ).

\subsection{Preparation of sol for hydrophobic coating}

For the preparation a sol suitable for use as the hydrophobic coating, a mixed solution of TEOS (1.23 mol), MTES $(1.23 \mathrm{~mol})$, 1-propanol (94.2 mol), water (7.9 mol), and ammonia (0.33 mol) was prepared under stirring at RT for $2 \mathrm{~h}$, followed by ageing for 4 days. To this, hexamethyldisilazane (HMDS) (0.9 mol) was added for surface modification of the $\mathrm{SiO}_{2}$ generated in the above sol and aged at RT for another 3 days. The acid-based 'Solution-A' prepared for AR coating was added to the above solution, maintaining the molar ratio of (TEOS + MTES): 1-propanol: water: ammonia: HMDS as $7.64: 29: 24.47: 1: 2.72$ to obtain a $1.5 \mathrm{wt} \% \mathrm{SiO}_{2}$ equivalent (considering $\mathrm{SiO}_{2}$ equivalents from TEOS + MTES + HMDS) sol for the hydrophobic coating sol.

\subsection{Coating preparation}

Prior to the deposition of coatings, the glass substrates were first cleaned with detergent, followed by washing with tap water and rinsing with distilled water, and then finally cleaned with ethanol. In the first step, an AR coating was prepared on the cleaned glass substrates using the AR coating sol via the spraycoating technique (USI, Ultrasonic System Inc.). The deposited coating was dried at $70-80{ }^{\circ} \mathrm{C}$ for $12 \mathrm{~h}$ and heat-treated at $450{ }^{\circ} \mathrm{C}$ for $1 \mathrm{~h}$ in an air oven (ramp rate $\left.1.5{ }^{\circ} \mathrm{C} \mathrm{min}^{-1}\right)$. The thicknesses of the thus-obtained coatings were in the range of 350-500 nm through XY movement of the spray head twice with 
the optimized spray head operational parameters, i.e., flow rate $0.5 \mathrm{~mL} \mathrm{~min}^{-1}$, head speed $100 \mathrm{~mm} \mathrm{~s}^{-1}$, spray width $15 \mathrm{~mm}$ and air pressure $20 \mathrm{psi}$. In the second step, the hydrophobic coating was developed on the AR-coated substrate using the hydrophobic coating sol via the above technique with a single XY movement of the spray head with the following operational parameters: flow rate $0.5 \mathrm{~mL} \mathrm{~min}^{-1}$, head speed $200 \mathrm{~mm} \mathrm{~s}^{-1}$, spray width $15 \mathrm{~mm}$ and air pressure $20 \mathrm{psi}$. The two-layered (AR and hydrophobic) coated substrates were then dried at $60{ }^{\circ} \mathrm{C}$ for $1 \mathrm{~h}$ followed by heating at $180{ }^{\circ} \mathrm{C}$ for $2 \mathrm{~h}$. The thicknesses of the hydrophobic coating were designed to be $30-45 \mathrm{~nm}(\leq 50 \mathrm{~nm})$ to avoid compromising the optical properties of the two layers.

\subsection{Coating characterization}

A spectroscopic ellipsometer (J. A. Woollam Co., Inc., USA) was used to measure the thickness and RI of the coatings deposited on single-side-polished Si-wafers. Coatings were developed on the substrates using an automatic ultrasonic spray-coating technique (BT Prism 400, USI, USA). The attenuated total reflection Fourier transform infrared (ATR-FTIR) spectra of the dried and heat-treated coatings were recorded using a Bruker ECO (ALPHA) spectrometer in the range of 600-4000 $\mathrm{cm}^{-1}$ with a resolution of $4 \mathrm{~cm}^{-1}$ and 200 scans. A UV/visible/ NIR spectrometer (PerkinElmer Lambda 900) was used to measure the transmission spectra of the coatings. An X-ray diffractometer (Rigaku SmartLab) operating at $9 \mathrm{~kW}(200 \mathrm{~mA}$, $45 \mathrm{kV})$ using $\mathrm{Cu}-\mathrm{K}_{\alpha}(\lambda=1.54059 \AA)$ radiation was used for low-angle XRD of the coatings; a grazing angle of $0.3^{\circ}$ was maintained with a scanning speed of $1^{\circ} \min ^{-1}$ using a step size of $0.02^{\circ}$. Thermogravimetric (TG) measurements were performed using a Netzsch STA model 449F3 thermal analyzer at a dynamic heating rate of $1.5{ }^{\circ} \mathrm{C} \mathrm{min}^{-1}$. Transmission electron microscopy (TEM) measurements were carried out using a JEOL 2010 transmission electron microscope equipped with an EDX (a)

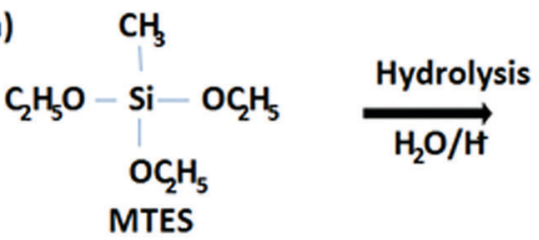<smiles>CO[Si](OC)(OC)OCCO</smiles>

(b)

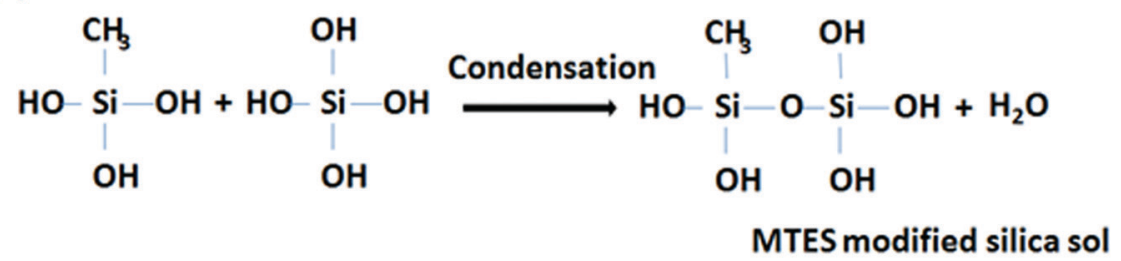

(c)

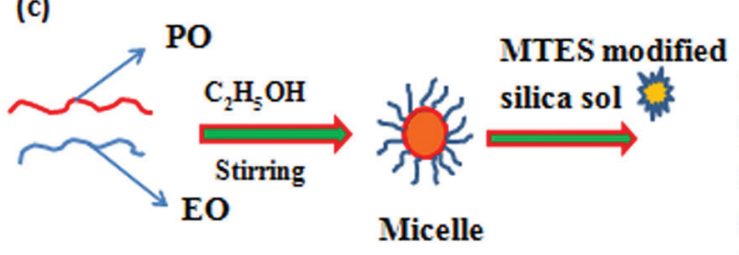

Pluronic F127
Hydrolysis

$\mathrm{H}_{2} \mathrm{O} / \mathrm{H}$

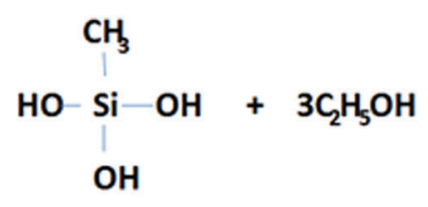

$\underset{\mathrm{HO}}{\stackrel{\mathrm{OH}}{\mathrm{OH}}-\mathrm{OH}}+4 \mathrm{C}_{2} \mathrm{H}_{5} \mathrm{OH}$
MTES modified silica sol

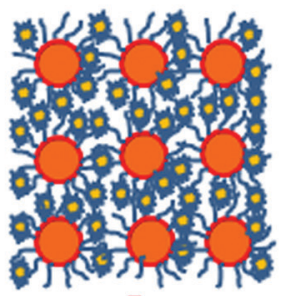

Drying at $80^{\circ} \mathrm{C}$ after spray coating

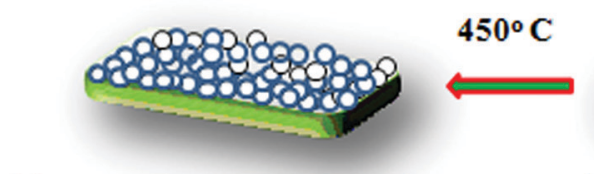

Mesoporous silica AR coating

Surfactant modified inorganic-organic hybrid coating

Scheme 1 The proposed reaction pathway during the preparation of the AR coating. 
(energy dispersive X-ray scattering) facility. TEM samples were prepared by scraping the film and placing the scraped films on a carbon-coated copper grid. The atomic force microscopy (AFM, Nanosurf Easy scan 2, Switzerland) study (contact mode) of the AR with the hydrophobic coated glass was performed using a Nanonics instrument. Photocurrent measurement was conducted using a Keithley instrument (4200 SCS) with an attached solar simulator (model SS50AAA-EM, Photo Emission Tech., Inc., Camarillo, California). Various characterization techniques, including the cross-cut and adhesive tape test (ASTM D 3359), abrasion test using a lens coating pencil hardness tester (ASTM D 3363), thermal test, and boiling saltwater test, were carried out to evaluate/measure the mechanical strength and chemical-resistance properties of the coatings.

\section{Results and discussion}

\subsection{Preparation of sol}

Various nanocomposite sols for the AR coating were prepared with $\mathrm{SiO}_{2}$ equivalent contents of $6.5 \mathrm{wt} \%$ and surfactant concentrations ranging from 3-8 wt\%. However, for the preparation of the sol for the hydrophobic layer (second layer coated on the AR-coated film), 1.5 wt $\% \mathrm{SiO}_{2}$ equivalents were used in the absence of any surfactant. The viscosities of the sols for the AR coating were in the range of 5-6 mPa.s. The proposed reaction pathway for the preparation of the AR and hydrophobic coatings is shown schematically in Schemes 1 and 2, respectively. In the first stage, TEOS and MTES undergo acid-catalyzed hydrolysis to form $\mathrm{Si}(\mathrm{OH})_{4}$ and $\mathrm{Si}(\mathrm{OH})_{3} \mathrm{CH}_{3}$, respectively (Scheme 1a).
The hydrolyzed species then undergo condensation to form an MTES-modified silica sol (Scheme 1b). The non-polar group $-\mathrm{Si}-\mathrm{CH}_{3}$ plays an important role in reducing the surface free energy of the AR coating surface. During the formation of the AR coating sol, the triblock co-polymer F127 $\left(\mathrm{EO}_{100} \mathrm{PO}_{70} \mathrm{EO}_{100}\right)$ forms isotropic micelles in the presence of ethanol (Scheme 1c). The micelles interact with the polymeric silica sol through hydrogen bonding and/or the weak van der Waals force. $N$-Methyl-2-pyrrolidone, a dipolar aprotic solvent having the ability to dissolve a variety of materials, was used in the solution to improve the wettability of the substrate to achieve a uniform coating through the spray-coating technique. Essentially, common solvents such as 1-propanol, 1-butanol and ethanol mixtures evaporated first when the solution droplets were sprayed from a certain distance $(\sim 60 \mathrm{~mm})$ as a mist on the texture glass with repeated XY direction movements, which makes it difficult to control the specific thickness of the coating materials. The coating was then oven-dried at $80{ }^{\circ} \mathrm{C}$ to form a surfactant-modified inorganic-organic hybrid coating. Upon heat treatment at $450{ }^{\circ} \mathrm{C}$, the self-aggregated surfactants were removed, generating a porous network in the deposited silica films of the AR coating.

Scheme 2 shows a schematic representation of the preparation of the hydrophobic coating. In this mechanistic pathway, HMDS interacts with the hydrolyzed species of TEOS to form an HMDS-modified silica sol having hydrophobic $\left(\mathrm{CH}_{3}\right)_{3} \mathrm{Si}-\mathrm{O}$ linkages. Finally, the MTESand HMDS-modified silica sol interacts with the surface hydroxyl groups of the porous silica network to endow it with a harder, more hydrophobic coating via inorganic-organic hybrid moieties. ${ }^{34}$

(a)

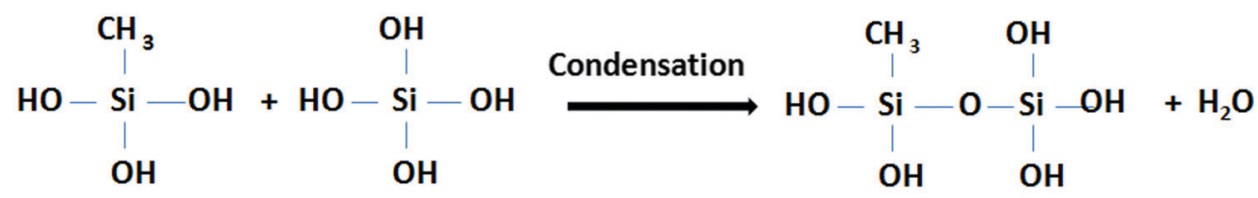

(b)

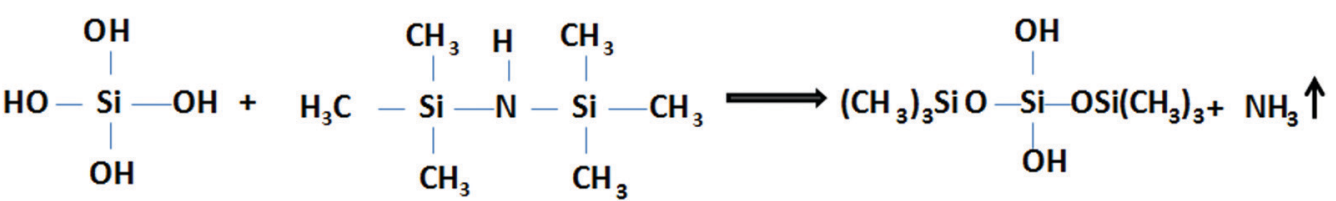

Silanol

HMDS

HMDS modified silica

(c)

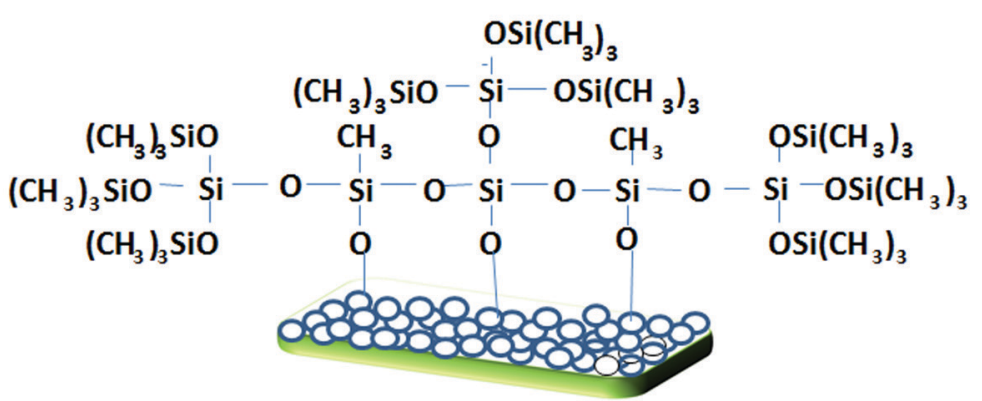

Scheme 2 A schematic representation of the tentative reaction pathway during the preparation of the hydrophobic coating 
(a)

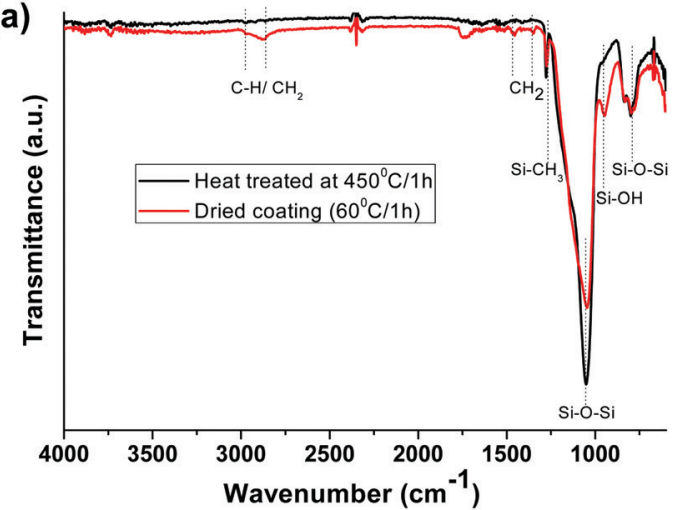

(b)

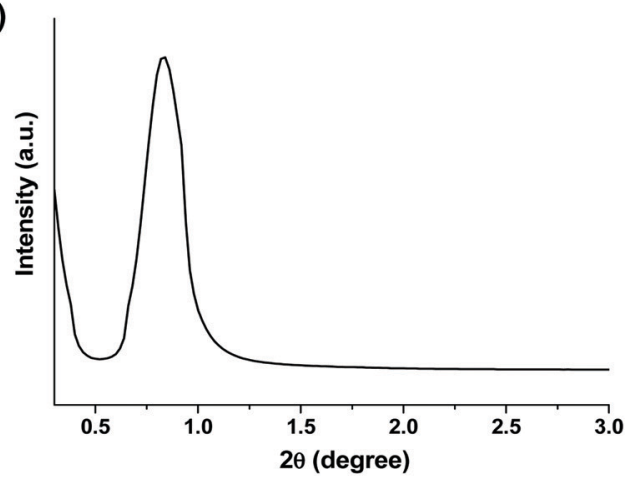

Fig. 1 (a) ATR-FTIR spectra of as-prepared and heat-treated $\left(450^{\circ} \mathrm{C} / 1 \mathrm{~h}\right)$ AR coatings and (b) low-angle XRD patterns of the AR coated glass heated at $450{ }^{\circ} \mathrm{C}$ for $1 \mathrm{~h}$.

\subsection{FTIR and GIXRD}

Fig. 1a presents the FTIR spectra of the as-dried $\left(60^{\circ} \mathrm{C} / 1 \mathrm{~h}\right)$ and heat-treated $\left(450{ }^{\circ} \mathrm{C} / 1 \mathrm{~h}\right)$ AR coatings. The absorption bands at $2856-1961 \mathrm{~cm}^{-1}$ and $1350-1450 \mathrm{~cm}^{-1}$ are due to $\mathrm{C}-\mathrm{H} / \mathrm{CH}_{2}$ stretching and bending vibrations, respectively. The peak at $1276 \mathrm{~cm}^{-1}$ is attributed to $\mathrm{Si}-\mathrm{CH}_{3} .{ }^{32}$ The characteristic asymmetric and symmetric stretching vibrations of $\mathrm{Si}-\mathrm{O}-\mathrm{Si}$ were indicated by the absorption bands at 1046 and $796 \mathrm{~cm}^{-1}$, respectively. However, the as-dried AR layer showed the characteristic band of $\mathrm{Si}-\mathrm{OH}$ at $946 \mathrm{~cm}^{-1} \cdot{ }^{35,36}$ Interestingly, the peaks originating from organic moieties $\left(\mathrm{C}-\mathrm{H} / \mathrm{CH}_{2}\right)$ disappeared after heat treatment, indicating the complete removal of organics from $\mathrm{SiO}_{2}$, except the $\mathrm{Si}-\mathrm{CH}_{3}$ peak $\left(1276 \mathrm{~cm}^{-1}\right)$, which was unaffected at this temperature. ${ }^{37}$ Thermal treatment of the coating resulted in a decrease in the Si-OH peak $\left(946 \mathrm{~cm}^{-1}\right)$ intensity and a shift of the Si-O-Si peak
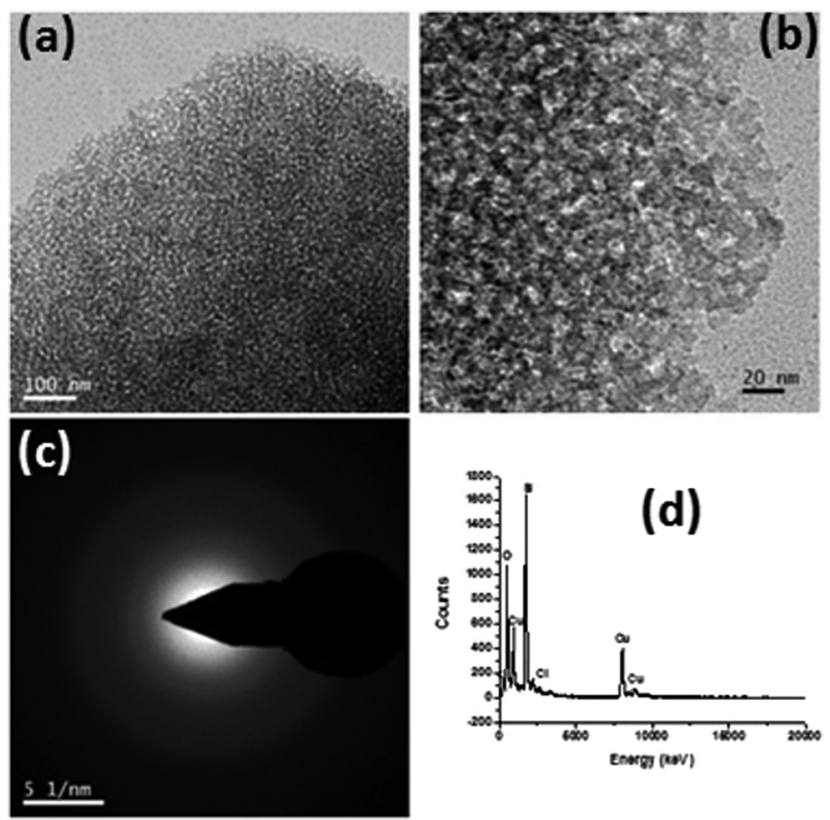

Fig. 2 (a and b) TEM images of the AR nanostructured mesoporous hydrophobic coating at different magnifications along with the (c) SAED pattern (d) and EDS spectrum. from 1046 to $1051 \mathrm{~cm}^{-1}$, indicating some silanol condensation, which helps to further strengthen the silica network.

A low-angle XRD study was carried out to analyse the mesostructural properties of the heat-treated AR coating at $450{ }^{\circ} \mathrm{C}$ (Fig. 1b). The broad reflection peak at around 0.7 ( 2 theta) indicates the porous nature of the silica layer. ${ }^{38,39}$ The mesoporous silica coating was formed via the spray coating technique due to the fast evaporation of the solvents, as well as the heat treatment of the coating.

\subsection{TEM analysis}

To investigate the microstructural features of the coating, a TEM study was performed (Fig. 2). Fig. $2 \mathrm{a}$ and $\mathrm{b}$ show the TEM images of the scraped SF- 6 coating at different magnifications, along with the selected area diffraction (SAED) pattern (Fig. 2c) and EDX spectrum (d). Low- and high-magnification TEM images (Fig. 2a and b) confirm the mesoporous nature of the $\mathrm{SiO}_{2}$ coating with an average pore diameter of $6 \mathrm{~nm}$. The volume fraction porosity $(P)$ of the coating was evaluated using the Lorenz-Lorentz equation ${ }^{35}$ and was found to be $\sim 25 \%$ with a pore size of $\sim 6 \mathrm{~nm}$. The SAED pattern (Fig. 2c) indicates the amorphous nature of the coating, while the EDX spectrum (Fig. 2d) reveals the presence of $\mathrm{C}, \mathrm{O}$ and $\mathrm{Si}$ in the coated sample.

\section{AFM study}

The hydrophobicity of a surface is dependent on both its chemical composition and topography. An AFM study of one representative hydrophobic film with a thickness of $\sim 400 \mathrm{~nm}$ was performed to examine the surface topography. Fig. 3 shows an AFM image of the film covering an area of $20 \times 20 \mu \mathrm{m}^{2}$. The surface of the AR with the hydrophobic coating was found to be spiky or micro/nano in nature with a root-mean square (rms) roughness value of about $\sim 64 \mathrm{~nm}$. This type of surface topography favours a mesoporous-silica-based AR-cum-hydrophobic coating surface. The photovoltaic performance will completely depend on the AR-cum-hydrophobic mesoporous silica, which could improve the light trapping mechanism and reduce the surface reflection of incident light. ${ }^{40}$ The light scattering of the 


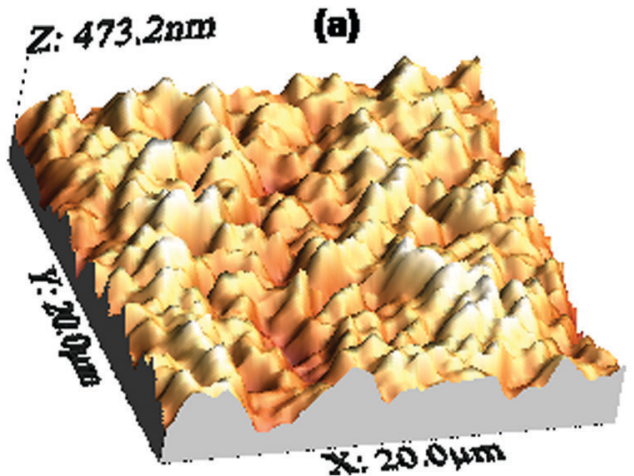

(b)

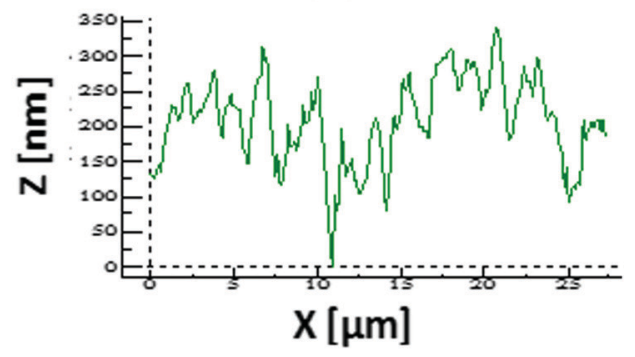

Fig. 3 (a) An AFM image $\left(20 \times 20 \mu \mathrm{m}^{2}\right.$ area) showing the surface topography of a representative coating with a thickness of $\sim 400 \mathrm{~nm}$ and (b) the peak height profile of the coating. The rms surface roughness value obtained from the image is $\sim 64 \mathrm{~nm}$.

mesoporous hydrophobic surface is strongly related to the surface roughness, which was characterized using AFM. Therefore, it increases the diffuse transmitted light from the incident beam scattered on the rough surface with a reduction of Fresnel reflection in the polycrystalline silicon solar cell.

\subsection{Properties of the coatings}

Fig. 4 shows the spray-coating technique for the preparation of the AR with a hydrophobic layer onto a $>300 \times 300 \mathrm{~mm}^{2}$ solar cover glass. The optimized thickness of the coating (350 to $500 \mathrm{~nm}$ ) shows an RI value of $1.295 \pm 0.005$ during the thermal decomposition of the surfactant, enhancing the porosity of the thin film. Hence, lowering the refractive index of the film, which is optically transparent and crack-free, helps to improve the optical performance of the polycrystalline silicon solar cell. The cross-cut scotch tape test (following the DIN 53151 or ASTM D 3359 specification) of the coating showed no damage, indicating good adhesion of the coated material to the substrate. The surface hardness of the AR coating was $\sim 5 \mathrm{H}$ (ASTM D 3363), and after the deposition of the hydrophobic coating on it, a hardness value of $\sim 3 \mathrm{H}$ was obtained. Table 2 shows the properties of the coatings derived from specific sols. After the application of hydrophobic coatings of thicknesses of 30-45 $\mathrm{nm}$ on top of the AR coating, the water contact angle (WCA) was in the range of $127 \pm 3^{\circ}$ with a hysteresis value of
$10 \pm 2^{\circ}$ without affecting the AR, output power or photocurrent. The surface hydrophobicity increased due to the functionalization and micro/nanostructure of the AR coating fabricated on the millimeter-scale textured solar glass. Measuring the transmission spectra in the solar-sensitive wavelength range of $400-1100 \mathrm{~nm}$ on the double-layer AR-cum-hydrophobic coated SCGs for different sets of coating compositions (SF-3-SF-8), it is clear that the average solar transmission is increased $\geq 4 \%$ with a decrease in the reflection (average $\sim 4 \%$ ) in SF-6 (Fig. 5 and Table 3). Lower light transmission values were observed in case of the SF-3 and SF-5 coatings compared to SF-6 due to the higher refractive index values and lower percentages of pores on the thin film surface. On the other hand, SF-7 and SF-8 coated glasses were found to show little adverse effect due to the higher percentages of surfactants present in their compositions. Fig. 5 shows the transmission spectra of the different compositions, along with that of uncoated SCGs for comparison.

To determine their long-term durability in atmospheric conditions, the mechanical properties of the AR-cum-hydrophobic coating were evaluated via an abrasion test followed by measurement of the contact angle of the coating. For this test, 80 mesh sandpaper and a $100 \mathrm{~g}$ weight are required. ${ }^{41}$ First, the 80 mesh sandpaper was placed on the coated substrate and the $100 \mathrm{~g}$ weight was loaded on the sandpaper. The sandpaper was then pulled slowly over a distance of up to $6 \mathrm{~cm}$ on the coating area for 50 cycles. After 50 such cycles, the static WCA value
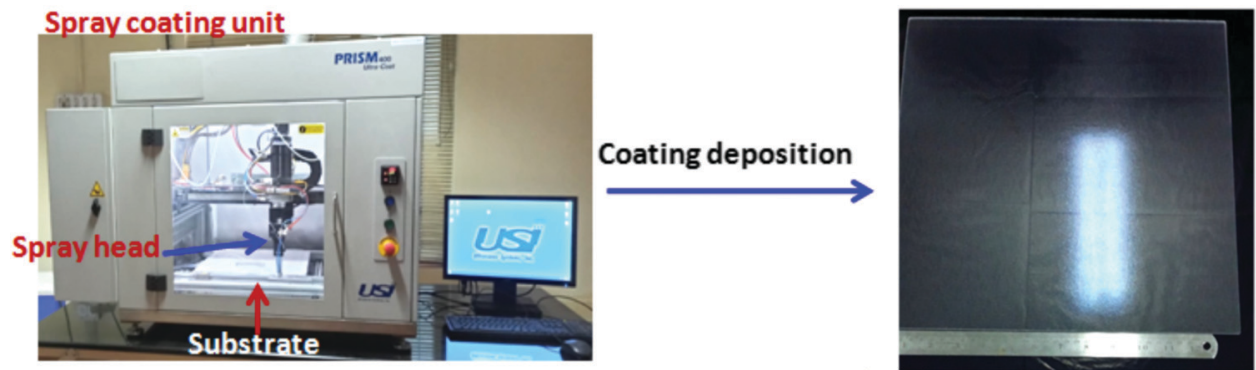

Fig. 4 Spray-coating technique for the fabrication of the AR coating with a hydrophobic layer onto $>300 \times 300 \mathrm{~mm}^{2}$ solar cover glass 
Table 2 Detailed test results for the mesoporous-silica-based AR and hydrophobic coatings on solar glass

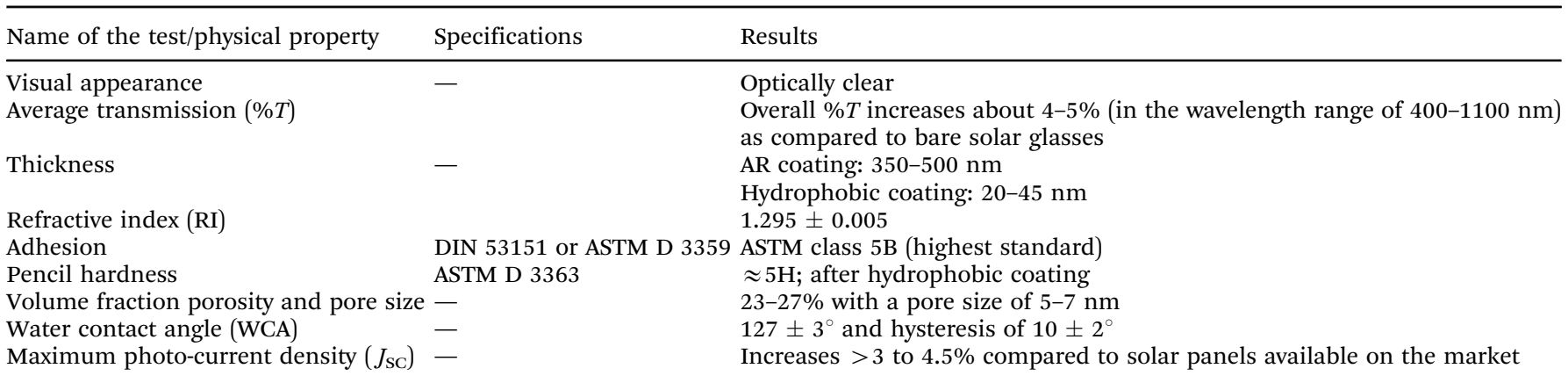

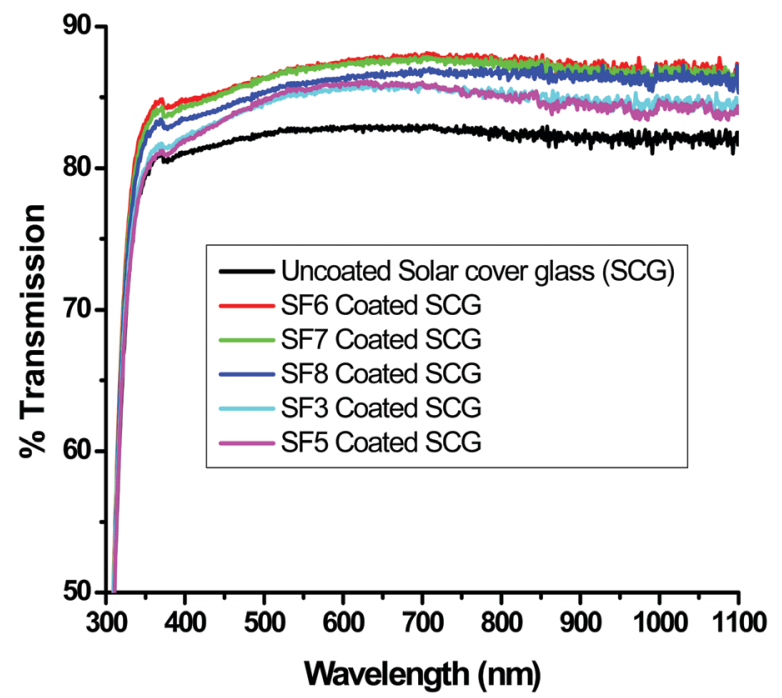

Fig. 5 Transmission spectra of bare (uncoated) solar cover glass (SCG) and those of AR-coated SCGs using different coating compositions.

(average data of $\sim 10$ points) was reduced to $105^{\circ}$ from its initial value of $130^{\circ}$, indicating the good abrasion-resistance properties of the coatings (Fig. 6). This indicates that the AR/ hydrophobic properties remained unchanged after the abrasion test without any damage to the coating.

To determine the thermal stability of the films, the final AR sol was evaporated to dryness via heat-treatment at $80{ }^{\circ} \mathrm{C}$ for $12 \mathrm{~h}$ and subjected to a thermogravimetric (TG) study.

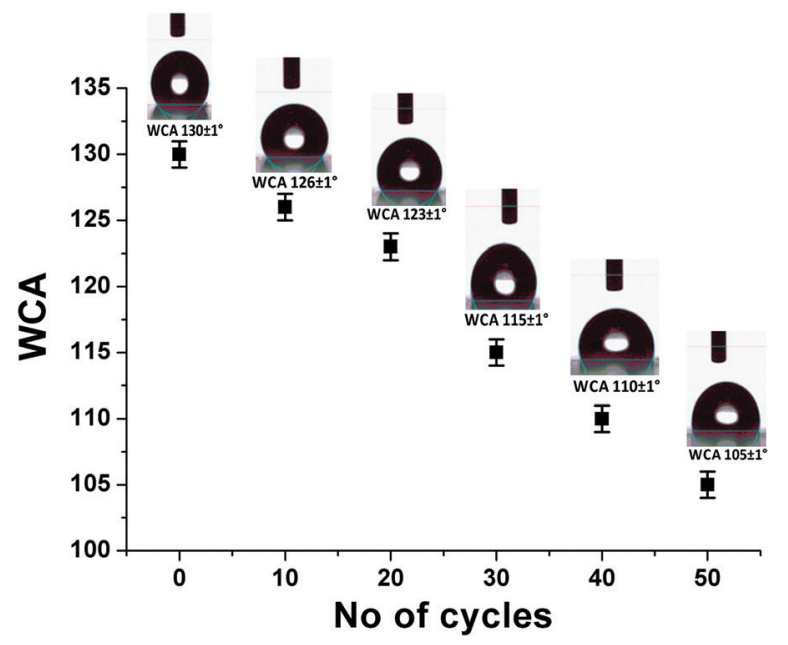

Fig. 6 Water contact angle (WCA) value (SF-6) after different numbers of abrasion cycles.

The results are shown in Fig. 7. It was observed that the weight loss up to $300{ }^{\circ} \mathrm{C}$ corresponded to the liberation of moisture, trapped solvents and other volatile components present in the material. The TG curve shows an approximately $22.5 \%$ weight loss up to about $300{ }^{\circ} \mathrm{C}$; above this temperature, the decomposition of organic components began, and beyond $450{ }^{\circ} \mathrm{C}$, no noticeable weight loss was observed.

We also evaluated the stability of the coated films with respect to UV radiation exposure (in a UV chamber) by measuring

Table 3 Percent transmission data of uncoated, AR-coated and AR-cum-hydrophobic coated millimeter-scale textured solar cover glasses (MSTSCG)

\begin{tabular}{|c|c|c|c|c|}
\hline \multirow[b]{2}{*}{ Sample } & \multicolumn{2}{|c|}{$\begin{array}{l}\text { Average \% transmission } \\
\text { in the wavelength region }\end{array}$} & \multicolumn{2}{|c|}{$\begin{array}{l}\text { Increase in \% transmission due to AR- } \\
\text { and AR-cum-hydrophobic coatings in } \\
\text { comparison to the uncoated solar glass } \\
\text { in the wavelength region }\end{array}$} \\
\hline & $400-800 \mathrm{~nm}$ & $800-1100 \mathrm{~nm}$ & $400-800 \mathrm{~nm}$ & $800-1100 \mathrm{~nm}$ \\
\hline Millimeter-scale textured solar cover glass (SCG) (uncoated) & 82.59 & 82.15 & - & - \\
\hline SCG with SF-3 AR and hydrophobic coating & 84.95 & 84.72 & 2.36 & 2.57 \\
\hline SCG with SF-5 AR and hydrophobic coating & 85.07 & 84.38 & 2.48 & 2.23 \\
\hline SCG with SF-6 AR and hydrophobic coating & 87.01 & 87.12 & 4.42 & 4.97 \\
\hline SCG with SF-7 AR and hydrophobic coating & 86.82 & 86.83 & 4.23 & 4.68 \\
\hline SCG with SF-8 AR and hydrophobic coating & 85.90 & 86.41 & 3.31 & 4.26 \\
\hline
\end{tabular}




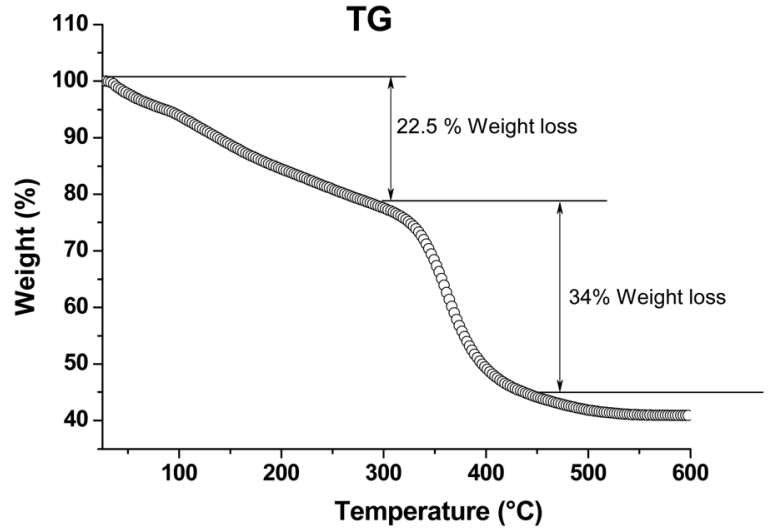

Fig. 7 TG analysis of an AR powder sample. Measurements were carried out at a heating rate of $1.5^{\circ} \mathrm{C} \mathrm{min}^{-1}$ in air.

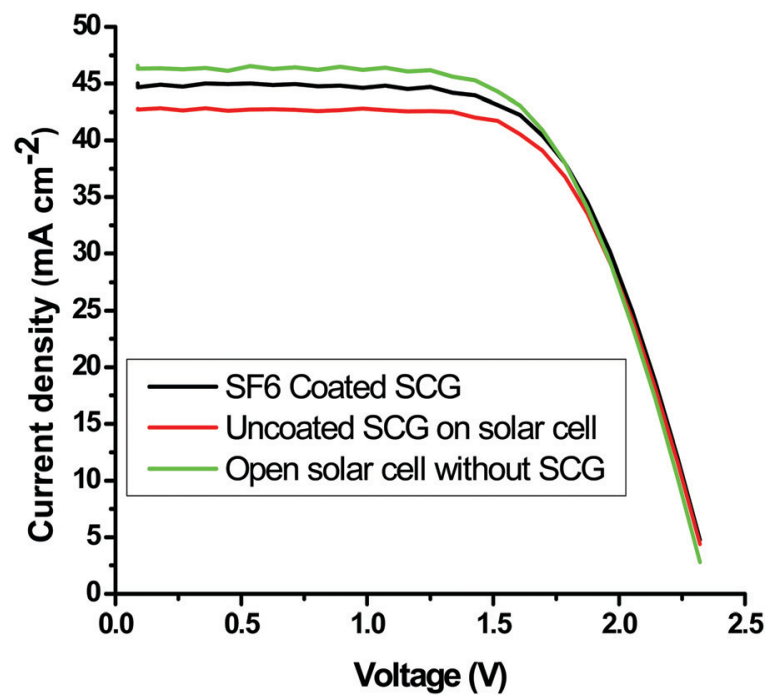

Fig. 8 Evaluation of the maximum output photo-power and short circuit current of the mesoporous-coated and uncoated textured solar cover glass.

their WCA values. For this purpose, coatings of about $350 \mathrm{~nm}$ in thickness were prepared on solar cover glass substrates and their WCA values were measured as a function of the exposure time to UV energy radiation (intensity UV-A: $83.75 \mathrm{~W} \mathrm{~m}^{-2}$; UV-B: 13.75 $\mathrm{W} \mathrm{m}^{-2}$, sample surface temperature: $60{ }^{\circ} \mathrm{C}$ ). From the test results, it was observed that after continuous UV exposure for $50 \mathrm{~h}$, the WCA of the coating changed slightly from $130^{\circ}$ to $124^{\circ}$, resulting in no significant changes in the percent transmission, which indicates the good durability of the coatings. ${ }^{42}$

\subsection{Solar performance}

Polycrystalline solar cells were used to investigate the effect of the optimized mesoporous silica AR-cum-hydrophobic coating on the performance of the solar cell. Standard 1 sun light from a solar simulator was illuminated (illuminated area: $2 \times 2 \mathrm{~cm}^{2}$ ) on a silicon solar cell with a coated textured solar cover glass and compared with an uncoated textured solar glass using a Keithley 4200-SCS unit to measure the electrical power through the $I-V$ curve. From the $I-V$ curve, it was found that maximum current density, $J_{\mathrm{sc}}\left(\mathrm{mA} \mathrm{cm}{ }^{-2}\right)$ of the SF-6 coated SCG substrate was increased up to $4.65 \%$, and, interestingly, the maximum power output was also enhanced up to $4.0 \%$ compared to that of the uncoated solar cover glass substrate (Fig. 8 and Table 4). This also further supports the average increase of $4.66 \%$ in the light transmission value in the wavelength range of 400 to $1100 \mathrm{~nm}$ (Fig. 5) compared to that of the uncoated SCG. The AR performance and light-trapping efficiency were improved on the porous coated textured glass via the diffuse transmission mechanism with a reduction of the Fresnel reflection, which increases the optical path length of light to enhance the current density $\left(J_{\mathrm{sc}}\right)$ in the solar cell.

Table 4 shows the details of the $I-V$ data of the samples coated with coatings of different compositions (SF-3, SF-5, SF-6, SF-7 and SF-8) along with the uncoated SCG and reference open solar cell. We achieved excellent $I-V$ results through enhanced light trapping and charge carrier density using our optimized coated solar cover glass substrate as compared to the results obtained using commercially available ARC glasses on polycrystalline silicon solar cells. Therefore, the enhancement in the performance of the polycrystalline solar cells exceeded the gain in the light transmittance of the textured solar cover glass.

\section{Conclusions}

The present work describes the fabrication of mesoporoussilica-based transparent, hard, and antireflective (AR) coatings (thickness: $350-500 \mathrm{~nm}$ ) with hydrophobic (WCA: 124-130 surfaces on millimeter-scale textured solar cover glasses via a spray-coating technique. The coatings increased the photocurrent density $\left(J_{\mathrm{sc}}\right)$ or power generation efficiency of solar modules and exhibited easy maintenance and/or self-cleaning

Table 4 Maximum photocurrent $\left(I_{\max }\right)$, maximum voltage $\left(V_{\max }\right)$, and maximum power $\left(P_{\max }\right)$ output from a standard solar cell without cover glass, with commercial millimeter-scale textured cover glass, and with porous silica-coated commercial textured glass substrates under 1 sun for a projected illumination area of $5 \times 5 \mathrm{~cm}^{2}$

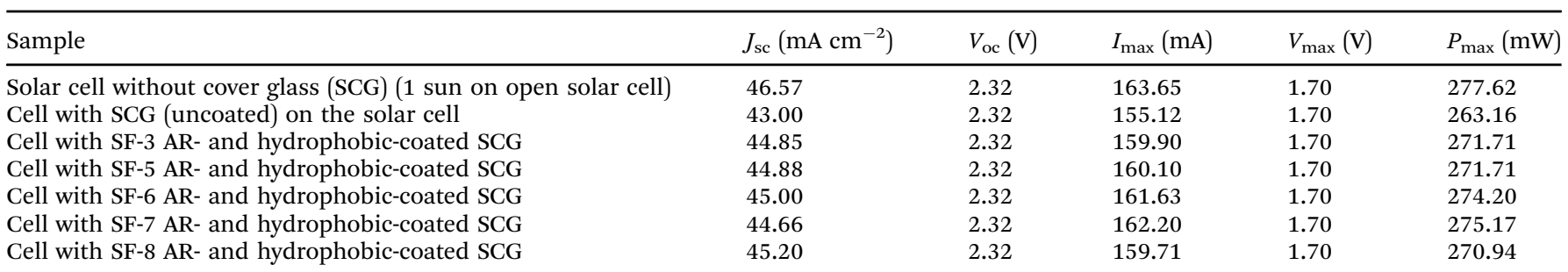


properties. The bilayer-coated millimeter-scale textured solar glass showed an increase in average solar transmission of $\geq 4 \%$ due to the reduced reflection (average $\sim 4 \%$ ) in the wavelength range of 400-1100 nm. The maximum output current density $\left(J_{\mathrm{SC}}\right)$ of the fabricated solar cell (compared to those available on the market) increased by $>3$ to $4.6 \%$ (under 1 sun illumination), while the surface hydrophobicity increased after functionalization due to the micro/nanostructure of the AR coating fabricated on millimeterscale solar glass. After 50-cycle sandpaper (80 mesh) abrasion testing, the WCA value was reduced from $130^{\circ}$ to $105^{\circ}$, and the coating could withstand $>50 \mathrm{~h}$ UV radiation exposure testing, indicating the durability and good abrasion resistance properties of the coatings. Therefore, these AR and hydrophobic coatings on solar cover glass could be useful to trap more sunlight in silicon solar cells for higher conversion efficiencies, and they would be applicable in harsh and rough environments. Therefore, this costeffective, highly abrasion-resistant $\mathrm{AR}$ and hydrophobic coating could be effectively utilized to achieve superior photo-power performance in solar cells to fulfill global energy demands.

\section{Conflicts of interest}

The authors declare that they have no conflicts of interest.

\section{Acknowledgements}

The authors would like to thank the Director, CSIR-CGCRI for pursuing this work. S. Manna thanks AcSIR (CSIR) for carrying out this work. Financial support rendered by DST, Govt. of India (Sanctioned No.: IUSSTF/JCERDC-IBEE/2016-17; dated $19 / 01 / 2017$ ) is gratefully acknowledged.

\section{References}

1 H. K. Raut, A. S. Nair, S. S. Dinachali, V. A. Ganesh, T. M. Walsh and S. Ramakrishna, Sol. Energy Mater. Sol. Cells, 2013, 111, 9-15.

2 I. Das and G. De, Adv. Mater. Interfaces, 2016, 1500848-1500857.

3 Y. N. Chanchangi, A. Ghosh, S. Sundaram and T. K. Mallick, Renewable Sustainable Energy Rev., 2020, 121, 109704-109717.

4 S. Pendsea, K. C. S. Reddya, C. Narendraa, K. Murugana and S. Sakthivela, Sol. Energy, 2018, 163, 425-433.

5 X. Li, J. He and W. Liu, Mater. Res. Bull., 2013, 48, 2522-2528.

6 J. Son, S. Kundu, L. K. Verma, M. Sakhuja, A. J. Danner, C. S. Bhatia and H. Yang, Sol. Energy Mater. Sol. Cells, 2012, 98, 46-51.

7 X. Li, X. Du and J. He, Langmuir, 2010, 26, 13528-13534.

8 H. Yabu and M. Shimomura, Chem. Mater., 2005, 17, 5231-5234.

9 N. D. Kalyankar and N. Kumar, US Pat., WO2012125271 2013.

10 D. Bernsmeier, J. Polte, F. Ortel, T. Krahl, F. Kemnitz and R. Kraehnert, ACS Appl. Mater. Interfaces, 2014, 6(22), 19559-19565.
11 B. Reid, A. Taylor, Y. Chen, H. B. Schmidt and S. Guldin, ACS Appl. Mater. Interfaces, 2018, 10(12), 10315-10321.

12 L. Liang, R. Blacker, N. D. Kalyankar and S. Jew Hurst, US Pat., 0272126, 2014.

13 D. B. Mahadik, R. V. Lakshmi and H. C. Barshilia, Sol. Energy Mater. Sol. Cells, 2015, 140, 61-68.

14 M. Matheron, J. Biteau, J. P. Cano, J. P. Boilot and T. Gacoin, US Pat., 8182866, 2012.

15 M. Zou III, C. Thompson and R. A. Fleming, US Pat, 0005886, 2016.

16 S. Maghsoodi, A. Varadarajan and M. Movassat, US Pat., 0083620, 2016.

17 J. Wang, C. Yang, Y. Liu, C. Zhang, C. Zhang, M. Wang, J. Zhang, X. Cui, R. Ding and Y. Xu, RSC Adv., 2016, 6, 25191-25197.

18 R. Xi, Y. Wang, X. Li, X. Zhang and X. Du, J. Colloid Interface Sci., 2020, 563, 42-53.

19 J. Sun, Q. Zhang, R. Ding, H. Lv, H. Yan, X. Yuan and Y. Xu, Phys. Chem. Chem. Phys., 2014, 16, 16684-16693.

20 K. H. Nielsena, D. K. Orzola, S. Koynov, S. Carney, E. Hultstein and L. Wondraczek, Sol. Energy Mater. Sol. Cells, 2014, 128, 283-288.

21 J. Wang, J. Zhang and Z. Liu, Asian J. Chem., 2013, 25(10), 5787-5789.

22 W. Zhang, J. Tu, W. Long, W. Lai, Y. Sheng and T. Guo, Energy Procedia, 2017, 130, 72-76.

23 L. Ye, S. Zhang, Q. Wang, L. Yan, H. Lv and B. Jiang, RSC Adv., 2014, 4, 35818-35822.

24 C. A. Sáenz, J. A. S. García, M. Machado, M. Brizuela, O. Zubillaga and A. Tercjak, Sol. Energy Mater. Sol. Cells, 2018, 186, 154-164.

25 N. Shanmugam, R. Pugazhendhi, R. M. Elavarasan, P. Kasiviswanathan and N. Das, Energies, 2020, 13, 2631-2723.

26 G. Womacka, K. Isbilira, F. Liscoa, G. Durandb, A. Taylorb and J. M. Wallsa, Surf. Coat. Technol., 2019, 358, 76-83.

27 J. Hwang and H. Daiguji, Langmuir, 2013, 29(7), 2406-2411. 28 X. Du, Y. Xing, X. Li, H. Huang, Z. Geng, J. He, Y. Wen and X. Zhang, RSC Adv., 2016, 6, 7864-7871.

29 G. Helsch and J. Deubener, Sol. Energy, 2012, 86(3), 831-836.

30 C. Ballif, J. Dicker, D. Borchert and T. Hofmann, Sol. Energy Mater. Sol. Cells, 2004, 82(3), 331-344.

31 X. Wang and J. Shen, J. Sol-Gel Sci. Technol., 2010, 53, 322-327.

32 S. Suthaa, S. Suresh, B. Raj and K. R. Ravia, Sol. Energy Mater. Sol. Cells, 2017, 165, 128-137.

33 V. Jain, T. Anjilivelil, T. Sriharsha and N. Rameshbabu, J. Energy Res. Environ. Technol., 2017, 4(3), 215-220.

34 A. Anedda, C. M. Carbonaro, F. Clemente, R. Corpino and P. Carlo Ricci, J. Phys. Chem. B, 2003, 107, 13661-13664.

35 J. Saha, A. Mitra, A. Dandapat and G. De, Dalton Trans., 2014, 43, 5221-5229.

36 J. Wang, H. Zhang, L. Wang, K. Yang, L. Cang, X. Liu and W. Huang, ACS Appl. Energy Mater., 2020, 3(5), 4484-4491.

37 X. F. Wen, K. Wang, P. H. Pi, J. X. Yang, Z. Q. Cai, L. J. Zhang, Y. Qian, Z. R. Yang, D. F. Zheng and J. Cheng, Appl. Surf. Sci., 2011, 258, 991-998. 
38 Q. Meng, A. Duan, C. Xu, Z. Zhao, J. Li, B. Wang, C. Liu, 40 J. Saha and G. De, Chem. Commun., $2013,49,6322-6324$. D. Hu, H. Li and Y. Li, Catal. Sci. Technol., 2018, 8, 41 I. Das, M. K. Mishra, S. K. Medda and G. De, RSC Adv., 2014, 5062-5072.

4, 54989-54997.

39 S. Abbaspour, A. A. Nourbakhsh, R. J. KalbasI and 42 D. A. Schaeffer, G. Polizos, D. Barton Smith, D. F. Lee, K. J. D. Mackenzie, Mol. Cryst. Liq. Cryst., 2012, 555, 104-111. S. R. Hunter and P. G. Datskos, Nanotechnology, 2015, 26, 055602-055610. 